\title{
Phase Transitions in Bismuth Pyrostannate Upon Substitution of Tin by Iron Ions
}

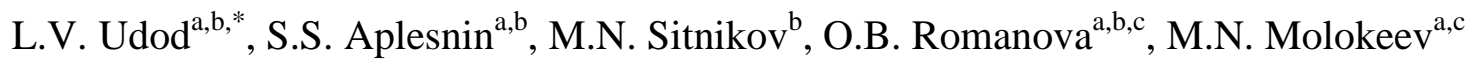 \\ ${ }^{a}$ Kirensky Institute of Physics, Federal Research Center KSC SB RAS, Akademgorodok, \\ 50, Krasnoyarsk 660036, Russia \\ ${ }^{\mathrm{b}}$ Reshetnev Siberian State University of Science and Technology 660037, Krasnoyarsk, \\ Russia \\ ${ }^{\mathrm{c}}$ Siberian Federal University, Krasnoyarsk, 660041, Russia \\ *Corresponding author: E-mail: luba@iph.krasn.ru
}

\begin{abstract}
The $\mathrm{Bi}_{2}\left(\mathrm{Sn}_{1-\mathrm{x}} \mathrm{Fe}_{\mathrm{x}}\right)_{2} \mathrm{O}_{7}(\mathrm{x}=0,0.1,0.2)$ compounds have been synthesized by the solidstate reaction technique. The structure of the synthesized compounds has been investigated in the temperature range of 80-500 $\mathrm{K}$ using the thermal expansion and ultrasound damping coefficients and IR spectroscopy. The shift -type structural transitions for the composition with $\mathrm{x}=0.2$ in the low-temperature region has been established. The effect of iron ions on the phase boundaries of the polymorphic transitions in the $\mathrm{Bi}_{2} \mathrm{Sn}_{2} \mathrm{O}_{7}$ compound has been observed. Softening of the phonon modes near the phase transitions at different iron concentrations has been found.
\end{abstract}

Keywords: crystal structure, domain structure, optical properties, phase transitions, thermal expansion, ultrasonics.

\section{Introduction}

The compounds with a pyrochlore structure belong to the functional materials and attract close attention due to their ferroelectric [1] and dielectric properties [2], superconductivity [3], oxygen ion conductivity [4], colossal magnetoresistance [5], metal-superconductor transitions [6], magnetic frustrations in the spin ice state [7], absorption of nuclear radiation [8], and photocatalysis [9].

A prominent representative of the pyrochlore family is bismuth pyrostannate $\mathrm{Bi}_{2} \mathrm{Sn}_{2} \mathrm{O}_{7}$ with the fluorite-type anion defect lattice, in which cationic sites are ordered and slightly shifted from the ideal crystallographic positions [10]. The structure is described well by two interpenetrating oxide sublattices with the general composition $\mathrm{A}_{2} \mathrm{~B}_{2} \mathrm{O}_{6} \mathrm{O}^{\prime}$, where $\mathrm{A}$ and $\mathrm{B}$ are metal cations. The $\mathrm{B}_{2} \mathrm{O}_{6}$ sublattice consists of $\mathrm{BO}_{6}$ vertex-sharing octahedra, which form hexagonal rings. In the $\mathrm{A}_{2} \mathrm{O}^{\prime}$ sublattice, cation $\mathrm{A}$ is tetrahedrally coordinated by the $\mathrm{O}^{\prime}$ anions with the linear $\mathrm{O}^{\prime}-\mathrm{A}-\mathrm{O}^{\prime}$ bonds. At the same time, cation $\mathrm{A}$ is located in a hexagonal ring and forms bonds with the $\mathrm{O}^{2-}$ anions and two shorter bonds formed by the $\mathrm{O}^{\prime}$ anions perpendicular to the ring. The correlated displacements of $\mathrm{Bi}^{3+}$ can induce phase transitions to complex ordered structures.

According to the literature data, bismuth pyrostannate $\mathrm{Bi}_{2} \mathrm{Sn}_{2} \mathrm{O}_{7}$ has a distorted pyrochlore structure [11]. At room temperature, this compound has a non-centrosymmetric monoclinic structure ( $\alpha$ phase) with sp. gr. Plcl [12]. The $\alpha$-phase crystal structure is very complex and has 176 crystallographically independent atoms [13]. Each $\mathrm{Bi}^{3+}$ ion is shifted from the center inside the ring and, in addition, along the $\mathrm{O}^{\prime}-\mathrm{O}^{\prime}$ axis, which leads to the formation of the long and short $\mathrm{Bi}-\mathrm{O}^{\prime}$ bonds. With an increase of the temperature, bismuth pyrostannate

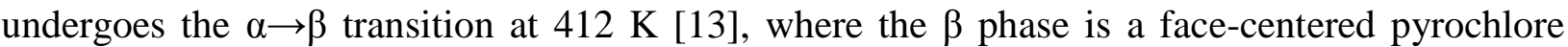
structure with the doubled unit cell $(\mathrm{a}=21.4 \AA)$. At $363 \mathrm{~K}$, the $\alpha \rightarrow \beta$ transition [14] in the singlecrystal samples has a ferroelectric nature with the non-centrosymmetric cubic structure of the $\beta$ 
phase. With an increase in temperature, the second-order $\beta \rightarrow \gamma$ phase transition to the $\gamma$ phase with a cubic pyrochlore structure occurs at $953 \mathrm{~K}$. The domain structure of the $\alpha$ and $\beta$ phases is studied by second harmonic generation methods, which confirm the absence of the symmetry center in both groups.

The investigations on the polycrystalline samples [13] revealed the $\alpha \rightarrow \beta$ transition at 408 $\mathrm{K}$. The structure of the $\beta$ phase was first attributed to the centrosymmetric sp. gr. $F \overline{4} 3 c\left(T_{d}^{5}\right)$, which is does not agree with the data reported in [14]. According to the neutron diffraction data, at $899 \mathrm{~K}$ the first-order $\beta \rightarrow \gamma$ transition with the displacement of $\mathrm{Bi}^{3+}$ ions occurs [15-16]. It was determined that the $\gamma$ phase has the sp. gr. $F \overline{3} d m$. The phase transitions are accompanied by a decrease in the unit cell volume [12]. This effect is well-known as the negative thermal expansion. The X-ray and neutron diffraction studies showed that the change in the volume is caused by the change in the $\mathrm{Bi}-\mathrm{O}^{\prime}$ bond length at the invariable $\mathrm{Sn}-\mathrm{O}$ distance [17].

The compounds with a pyrochlore structure, e. g., $\mathrm{Cd}_{2} \mathrm{Nb}_{2} \mathrm{O}_{7}$, undergo a number of structural transitions at low temperatures [18]. In $\mathrm{Cd}_{2} \mathrm{Nb}_{2} \mathrm{O}_{7}$, a sequence of phase transitions is observed in the temperature range of 10-300 K. With an increase in temperature, an improper ferroelectric occurs at $T_{S}=205 \mathrm{~K}$, which transforms to the ferroelectric phase at $T_{C}=196 \mathrm{~K}$; after that, the transitions to the incommensurate phase at $\mathrm{T}_{\text {inc }}=85 \mathrm{~K}$, commensurate phase at $\mathrm{T}_{\text {com }}=46 \mathrm{~K}$, and spin-glass state at $\mathrm{T}_{\mathrm{q}}=18 \mathrm{~K}$ occur. Below the temperature of the ferroelectric phase transition in the range of 180-192 K, the domain structure and refractive index do not noticeably change and the crystal symmetry does not lower. Below the $\mathrm{T}_{\mathrm{C}}=196 \mathrm{~K}$, along with the domains of the ferroelectric phase, domains of the preceding previous phase are observed, which gradually decrease below $180 \mathrm{~K}$ and become indistinguishable using optical methods at $150 \mathrm{~K}$. About $\mathrm{T}_{\mathrm{S}}=205 \mathrm{~K}$, the structure is cubic, $F \overline{3} \mathrm{dm}$, and it changes to orthorhombic or tetragonal at cooling. At $\mathrm{T}_{\text {inc }}=85 \mathrm{~K}$, the crystal structure changes into a monoclinic. At low temperatures, niobium ions displace, which leads to the formation of short and long $\mathrm{Nb}-\mathrm{O}$ bonds. In the intermediate phase, the short and long bonds alternate along the [001] and [111] directions. The Nb1-O bond is distorted along the [100] direction at the transition to the monoclinic structure.

The predicted physical properties of the pyroclore-structure compounds can be obtained using cation substitution. The easy substitution is ensured by the stability of the pyrochlore structure. For instance, pyrochlore $\mathrm{Bi}_{2} \mathrm{InNbO}_{7}$ behaves as a photocatalyst under UV radiation; the large gap $(2.7 \mathrm{eV})$ in this material arises at the partial replacement of In by Fe [19-20].

The absence of the inversion center in bismuth stannate is a prerequisite for the ferroelectric order at low temperatures. This was confirmed by ab initio calculations made in [14]. The substitution of tin by iron will result in the magnetic ordering; thus, due to the interaction between the magnetic and ferroelectric subsystems, the ferroelectric properties of $\mathrm{Bi}_{2}\left(\mathrm{Sn}_{1-\mathrm{x}} \mathrm{Fe}_{\mathrm{x}}\right)_{2} \mathrm{O}_{7}$ can be obtained. The substitution can lead to the crystal lattice distortions and shift of the phase transitions. In particular, the heterovalent substitution of $\mathrm{Bi}^{3+}$ and $\mathrm{Sn}^{4+}$ ions in $\mathrm{Bi}_{2} \mathrm{Sn}_{2} \mathrm{O}_{7}$ changes the temperature of the $\alpha \rightarrow \beta$ transition [14, 21-23]. The isovalent substitution of $\mathrm{Y} 3+$ ions for $\mathrm{Bi}^{3+}$ ones stabilizes the $\beta$ phase at room temperature under normal pressure [24].

The low-temperature investigations of bismuth pyrostannate have not been carried out so far. We may assume the occurrence of structural phase transitions in $\mathrm{Bi}_{2}\left(\mathrm{Sn}_{1-\mathrm{x}} \mathrm{Fe}_{\mathrm{x}}\right)_{2} \mathrm{O}_{7}(\mathrm{x}=0,0.1$, 0.2 ) at low temperatures. The aim of this study was to establish possible low-temperature phase transitions caused by the substitution of tin by iron ions using the optical, structural, and acoustic techniques. 


\section{Experimental}

\subsection{Synthesis and X-ray diffraction}

The $\mathrm{Bi}_{2}\left(\mathrm{Sn}_{1-\mathrm{x}} \mathrm{Fe}_{\mathrm{x}}\right)_{2} \mathrm{O}_{7}(\mathrm{x}=0,0.1,0.2)$ compound was synthesized by the solid-state reaction in several stages in accordance with the scheme

$$
2(1-\mathrm{x}) \mathrm{SnO}_{2}+\mathrm{xFe}_{2} \mathrm{O}_{3}+\mathrm{Bi}_{2} \mathrm{O}_{3} \rightarrow \mathrm{Bi}_{2}\left(\mathrm{Sn}_{1-\mathrm{x}} \mathrm{Fe}_{\mathrm{x}}\right)_{2} \mathrm{O}_{7-\mathrm{x}} \text {, where } \mathrm{x}=0,0.1,0.2
$$

The initial oxides used were ultrahigh-purity $\mathrm{Bi}_{2} \mathrm{O}_{3}, \mathrm{SnO}_{2}$, and $\mathrm{Fe}_{2} \mathrm{O}_{3}$. The tableted mixture of the initial oxides was placed in a furnace and kept at a temperature from 973 to 1223 $\mathrm{K}$ for $8-24 \mathrm{~h}$.

The synthesized samples were analyzed by X-ray diffraction. X-ray powder diffraction patterns of the $\mathrm{Bi}_{2}\left(\mathrm{Sn}_{1-\mathrm{x}} \mathrm{Fe}_{\mathrm{x}}\right)_{2} \mathrm{O}_{7}(\mathrm{x}=0,0.1,0.2)$ compounds were detected at room temperature on a Bruker D8 ADVANCE diffractometer using a VANTEC linear detector ( $\mathrm{Cu}-\mathrm{K} \alpha$ radiation). In the experiment, we used different primary beam gaps, specifically, $0.6 \mathrm{~mm}$ in the angle range of $2 \theta=5-70^{\circ}$ and $2 \mathrm{~mm}$ in the range of $70-120^{\circ}$. A scanning step of $0.016^{\circ}$ remained constant for all regions and the exposure times at each step were 1.5 and $1 \mathrm{~s}$ for the ranges of $5-70^{\circ}$ and $70-120^{\circ}$, respectively. The standard intensity deviations for all X-ray diffraction pattern points were calculated and, then, the intensities and standard deviations of all the points in the highangle region were multiplied by a normalization coefficient of 0.45 . All the peaks corresponded to the monoclinic $P c$ cell of the $\alpha-\mathrm{Bi}_{2} \mathrm{Sn}_{2} \mathrm{O}_{7}$ phase [12]. The crystal structure contains $32 \mathrm{Bi}^{3+}$ ions, $32 \mathrm{Sn}^{4+}$ ions, and $112 \mathrm{O}^{2-}$ ions in the independent cell part. $\mathrm{Bi}^{3+}$ ions are surrounded by eight $\mathrm{O}^{2-}$ ions and form distorted cubes; $\mathrm{Sn}^{4+}$ ions are surrounded by six oxygen ions and form vertex-sharing octahedra. The Rietveld refinement was performed using the TOPAS 4.2 program [25]. Coordinates of all 176 atoms were fixed, since the number of only 528 coordinates is comparable with the number of observed reflections. Nevertheless, even fixed atomic coordinates allowed us to correctly describe all the available reflections and the refinement yielded low unreliability factors (Table 1 and Figs. 1a, 1b).

Table 1. Main experimental parameters and results of the refinement for $\mathrm{Bi}_{2} \mathrm{Sn}_{2-\mathrm{x}} \mathrm{Fe}_{\mathrm{x}} \mathrm{O}_{7}$

\begin{tabular}{|c|c|c|}
\hline$x$ & 0.1 & 0.2 \\
\hline$S p . g r$. & $P c$ & $P c$ \\
\hline$a, \AA$ & $15.0712(5)$ & $15.0678(5)$ \\
\hline$b, \AA$ & $15.0810(4)$ & $15.0778(4)$ \\
\hline$c, \AA$ & $21.3417(5)$ & $21.3349(5)$ \\
\hline$\beta,^{\circ}$ & $90.010(3)$ & $90.022(3)$ \\
\hline$V, \AA^{3}$ & $4850.7(2)$ & $4847.1(2)$ \\
\hline $2 \theta$ range, & $5-140$ & $5-140$ \\
\hline$R_{w p}, \%$ & 7.68 & 7.57 \\
\hline$R_{p}, \%$ & 6.28 & 6.11 \\
\hline$R_{B}$ & 3.68 & 3.27 \\
\hline$X^{2}$ & 3.21 & 3.31 \\
\hline
\end{tabular}

Since the atomic coordinates and heat parameters were not refined, their values can be borrowed from study [12]. With an increase in the iron ion concentration, the cell volume 
decreases, which is consistent with the ionic radii IR $\left(\mathrm{Fe}^{3+}, \mathrm{LS}-\mathrm{HS}, \mathrm{CN}=6\right)=0.55-0.645 \AA$ and IR $\left(\mathrm{Sn}^{4+}, \mathrm{CN}=6\right)=0.69 \AA$.

\subsection{Technique of experiment}

It should be noted that the optical and acoustic investigations are sensitive to local structural distortions; therefore the chosen methods provide information about phase transitions in the $\mathrm{Bi}_{2}\left(\mathrm{Sn}_{1-\mathrm{x}} \mathrm{Fe}_{\mathrm{x}}\right)_{2} \mathrm{O}_{7}(\mathrm{x}=0,0.1,0.2)$ compounds.

The IR spectroscopy investigations of the $\mathrm{Bi}_{2}\left(\mathrm{Sn}_{1-\mathrm{x}} \mathrm{Fe}_{\mathrm{x}}\right)_{2} \mathrm{O}_{7}(\mathrm{x}=0,0.1,0.2)$ compound were carried out on an FSM 2202 IR Fourier spectrometer with a spectral resolution of $1 \mathrm{~cm}^{-1}$ in the temperature range of $80-500 \mathrm{~K}$ at frequencies of $400-7000 \mathrm{~cm}^{-1}$ on the polycrystalline sample in the form of tablets $13 \mathrm{~mm}$ in diameter in the $\mathrm{KBr}$ matrix.

The ultrasound damping in the $\mathrm{Bi}_{2}\left(\mathrm{Sn}_{1-\mathrm{x}} \mathrm{Fe}_{\mathrm{x}}\right)_{2} \mathrm{O}_{7}(\mathrm{x}=0.1,0.2)$ compounds was measured on the tablets with two piezoelectric sensors, one being an ultrasound generator and the other, a sonic signal sensor, which were glued with a silver paste to the tablet planes. The ultrasound passage time was $\tau=10^{-6} \mathrm{~s}$ at a pulse repetition rate of $5 \mathrm{MHz}$; the sample thickness was $0.4 \mathrm{~cm}$. The ultrasound damping coefficient was calculated as

$$
\alpha=\frac{\ln \left(\frac{U_{1}}{U_{2}}\right)}{d}
$$

where $U_{1}$ and $U_{2}$ are the voltage amplitudes detected by the ultrasound generator and sonic signal sensor and $d$ is the tablet thickness.

The thermal expansion coefficient was determined from the linear sample size variation $\mathrm{dL} / \mathrm{L}$ found by measuring the electrical resistance of the electric strain gauges placed on the sample and quartz: $(\operatorname{Rs}(\mathrm{T})-\mathrm{Rq}(\mathrm{T})) / \mathrm{Rq}(\mathrm{T})=(\mathrm{Ls}(\mathrm{T})-\mathrm{Lq}(\mathrm{T})) / \mathrm{Lq}(\mathrm{T})=\beta$, where $R s$ and $R q$ are the electrical resistances of the sample and quartz and $L s$ and $L q$ are the linear sizes of the sample and quartz, respectively.

\section{Results and discussions}

\subsection{IR spectra}

The ideal pyrochlore structure described using the group-theoretical analysis is presented in the form of 25 optical modes:

$$
\Gamma_{\text {opt }}=A_{1 g}(R)+E_{g}(R)+4 F_{2 g}(R)+7 F_{1 u}(I R)+\left(4 F_{2 u}+2 F_{1 g}+3 A_{2 u}+3 E_{u}\right) .
$$

Only seven optical modes $F_{1 u}$ are active in the IR spectral range [10,26,27].

The structural defects observed in the bismuth-containing pyrochlores lower the local symmetry on the Bi and O' atoms; therefore, the selection rules become less strict $[28,29]$. Some modes are observed using Raman and IR spectroscopy.

Figure 2 presents characteristic absorption bands for the $\mathrm{Bi}_{2}\left(\mathrm{Sn}_{1-\mathrm{x}} \mathrm{Fe}_{\mathrm{x}}\right)_{2} \mathrm{O}_{7}(\mathrm{x}=0,0.1,0.2)$ compounds in the frequency range of $400-1200 \mathrm{~cm}^{-1}$ at temperatures of $100,200,300$, and 400 $\mathrm{K}$. We select four frequency ranges in the IR spectra: $w 1=480-560$, w2 $=570-650$, w3 $=770$ 840 , and $\mathrm{w} 4=1000-1150 \mathrm{~cm}^{-1}$. The absorption bands in the frequency range of $100-1000 \mathrm{~cm}^{-1}$ are related to the phonon modes [30]. The highest-intensity absorption band observed in the 
frequency range of $570-650 \mathrm{~cm}^{-1}$ is attributed to the stretching mode of the $\mathrm{SnO}_{6^{-}}$octahedra $[31,32]$.

A broad band in the spectra of the $\mathrm{Bi}_{2}\left(\mathrm{Sn}_{1-\mathrm{x}} \mathrm{Fe}_{\mathrm{x}}\right)_{2} \mathrm{O}_{7}(\mathrm{x}=0,0.1,0.2)$ compounds in the frequency range of $480-570 \mathrm{~cm}^{-1}$ is described by two Lorentzian functions and corresponds to the stretching vibrations of the $\mathrm{Bi}-\mathrm{O}^{\prime}$ bond [33].

There are some weak absorption lines in the frequency range of $670-1200 \mathrm{~cm}^{-1}$, which probably correspond to the superstructural phonon modes. In this range, the highest absorption intensity is found at $800 \mathrm{~cm}^{-1}$ [33], which was observed for some pyrochlore-structure compounds, including $\mathrm{Bi}_{3 / 2} \mathrm{Zn}_{0.92} \mathrm{Nb}_{1.5} \mathrm{O}_{6.92}$ and $\mathrm{Bi}_{3 / 2} \mathrm{MgNb}_{3 / 2} \mathrm{O}_{7}$. The IR spectra of these compounds contain very weak absorption bands in the frequency range of $800-1100 \mathrm{~cm}^{-1}$ [34], which were interpreted by the change in the $\mathrm{A}-\mathrm{O}^{\prime}$ bond length in the $\mathrm{A}_{2} \mathrm{O}^{\prime}$ sublattice. The difference between bond lengths of 2.351 and $1.961 \AA$ is $20 \%$. The displacement of the $\mathrm{O}^{\prime}$ anion and cation $\mathrm{A}$ inside a domain shortens one $\mathrm{A}-\mathrm{O}^{\prime}$ bond and lengthens the other [35]. According to this model, the vibrations of the short A-O' bond correspond to the phonon modes near $850 \mathrm{~cm}^{-1}$ and vibrations of the long bond near $483 \mathrm{~cm}^{-1}$. It was mentioned that the displacement of $\mathrm{A}$ and $\mathrm{O}^{\prime}$ ions occurs in all pyrochlores where cation $A$ has active unshared pairs. The unshared electron pairs of $\mathrm{Bi}^{3+}$ are shortened due to the overlap of the $\mathrm{Bi}$ 6s electron pairs and $d$ orbitals of the cation [36]. This mode is not observed in other pyrochlores with the ideal structure and classified as an overtone or combination mode [37].

The high-frequency vibrations in the range of $1000-1150 \mathrm{~cm}^{-1}$ correspond to the electronic transitions that occur during the rearrangement and disappearance of domain boundaries and those caused by defects in the $\mathrm{Bi}_{2}\left(\mathrm{Sn}_{1-\mathrm{x}} \mathrm{Fe}_{\mathrm{x}}\right)_{2} \mathrm{O}_{7}(\mathrm{x}=0,0.1,0.2)$ crystal structure. The domain structure of $\mathrm{Bi}_{2} \mathrm{Sn}_{2} \mathrm{O}_{7}$ was observed at room temperature [14].

As the substitute concentration in the $\mathrm{Bi}_{2}\left(\mathrm{Sn}_{1-\mathrm{x}} \mathrm{Fe}_{\mathrm{x}}\right)_{2} \mathrm{O}_{7}(\mathrm{x}=0,0.1,0.2)$ samples increases, the frequencies of phonon modes change. Figure 3 shows temperature dependences of modes w 1 and $\mathrm{w} 2$ at different substitute concentrations. For the sample with $\mathrm{x}=0.2$, the frequency of mode w1 decreases by $4 \%$ near $170 \mathrm{~K}$ (Fig. 3a) and the intensity grows almost threefold. In the temperature range of $240-370 \mathrm{~K}$ and at $\mathrm{T}=420 \mathrm{~K}$, the $\mathrm{w}(\mathrm{T})$ dependence contains some anomalies with a threefold intensity drop at 330-420 K. The w1 mode frequency for the composition with $\mathrm{x}=0.1$ remains invariable until $160 \mathrm{~K}$ and reveals anomalies at temperatures of 216, 270, 350, and $440 \mathrm{~K}$ upon further heating. The w1-mode intensity smoothly halves over the entire temperature range. In the initial $\mathrm{Bi}_{2} \mathrm{Sn}_{2} \mathrm{O}_{7}$ compound, the w1-mode frequency softens at $\mathrm{T}=380 \mathrm{~K}$ with the intensity drops by a factor of 1.6 .

In these temperature ranges, the w2 mode changes (Fig.3b), especially in the $\mathrm{Bi}_{2}\left(\mathrm{Sn}_{1-}\right.$ $\left.{ }_{\mathrm{x}} \mathrm{Fe}_{\mathrm{x}}\right)_{2} \mathrm{O}_{7}(\mathrm{x}=0.1)$ compound at $155-295 \mathrm{~K}$. The temperature dependences curves of the frequency of the $\mathrm{Bi}_{2}\left(\mathrm{Sn}_{1-\mathrm{x}} \mathrm{Fe}_{\mathrm{x}}\right)_{2} \mathrm{O}_{7}(\mathrm{x}=0,0.2)$ compounds are qualitatively similar; the only the differences are that with increasing concentration the temperatures of the anomalies shift toward higher temperatures.

The similar situation was observed in the $\mathrm{Bi}_{2} \mathrm{O}_{3}-\mathrm{ZnO}-\mathrm{SnO}_{2}-\mathrm{Nb}_{2} \mathrm{O}_{5}$ compound [38], where the frequency of the stretching mode of $\mathrm{Sn}-\mathrm{O}$ vibrations increases with the tin concentration. The $\mathrm{w}(\mathrm{B}-\mathrm{O})$ frequency increases almost linearly with increasing the lattice constant or mean radius of the ion in the $\mathrm{B}$ site, which indicates the enhancement of the $\mathrm{B}-\mathrm{O}$ bond energy. Similar results were obtained for the In-doped $\mathrm{Bi}_{2} \mathrm{Sn}_{2} \mathrm{O}_{7}$ compound [39].

\subsection{Thermal expansion coefficient}


Figure 4 shows the temperature dependence of the thermal expansion coefficient for the $\mathrm{Bi}_{2}\left(\mathrm{Sn}_{0.8} \mathrm{Fe}_{0.2}\right)_{2} \mathrm{O}_{7}$ sample. It can be seen that the dependence has some anomalies in the temperature range of $80-600 \mathrm{~K}$. The first maximum at about $140 \mathrm{~K}$ is correlates with the temperature at which the phonon modes at $465-570 \mathrm{~cm}^{-1}$ corresponding to the stretching vibrations of the $\mathrm{Bi}-\mathrm{O}$ ' bond soften (Fig. 3). As the temperature decreases, it splits in two Lorentzian lines and the peak intensity decreases threefold.

The next series of anomalies of the thermal expansion coefficient $\beta(\mathrm{T})$ in the range of 230-280 K corresponds to the w2 mode shift in $\mathrm{Bi}_{2}\left(\mathrm{Sn}_{0.8} \mathrm{Fe}_{0.2}\right)_{2} \mathrm{O}_{7}$. This mode is attributed to the stretching $\mathrm{Sn}-\mathrm{O}$ vibrations in the $\mathrm{SnO}_{6}$ octahedra. The substitution of $\mathrm{Sn}^{4+}$ ions by $\mathrm{Fe}^{3+}$ ions with the smaller ionic radius leads to the lattice deformation, which is reflected in the $\beta(T)$ maxima and softening of the w2 frequency in the IR spectra.

Possibly, we found one more structural transition of shift type in $\mathrm{Bi}_{2}\left(\mathrm{Sn}_{1-\mathrm{x}} \mathrm{Fe}_{\mathrm{x}}\right)_{2} \mathrm{O}_{7}$ induced by the substitution of tin by iron. The shift type structural transitions are observed in the perovskite-type $\mathrm{Rb}_{2} \mathrm{KInF}_{6}$ crystal, where the symmetry is changed by the rotation of $\mathrm{InF}_{6}$ octahedra [40]. This transition occurs apparently in two stages. At room temperature, the $\mathrm{Bi}_{2}\left(\mathrm{Sn}_{1-\mathrm{x}} \mathrm{Fe}_{\mathrm{x}}\right)_{2} \mathrm{O}_{7}$ compound is in the $\alpha$ phase with the monoclinic non-centrosymmetric domain structure [14]. As the temperature is decreased to $250 \mathrm{~K}$, the $\mathrm{MeO}_{6}(\mathrm{Me}=\mathrm{Sn}, \mathrm{Fe})$ sublattice transforms to the lowest triclinic symmetry due to the rotation of the $\mathrm{MeO}_{6}$ octahedron; it is noteworthy that only a part of domains change. As the temperature is further decreased to $140 \mathrm{~K}$ the sample becomes single-phase.

The high-temperature anomalies in the $\beta(\mathrm{T})$ curve in the temperature range of $320-400 \mathrm{~K}$ are consistent with the temperature dependence of the sound damping coefficient (Fig. 5b). The $\alpha \rightarrow \beta$ transition in the iron-substituted samples apparently starts at lower temperatures than in the $\mathrm{Bi}_{2} \mathrm{Sn}_{2} \mathrm{O}_{7}$ compound. At $330 \mathrm{~K}$, domains with the $\mathrm{Fe}^{3+}$ ions pass to $\beta$ phase and above $440 \mathrm{~K}$ the compound is single-phase.

\subsection{Acoustic properties}

Figure 5 shows the temperature dependence of the ultrasound damping coefficient in the $\mathrm{Bi}_{2}\left(\mathrm{Sn}_{1-\mathrm{x}} \mathrm{Fe}_{\mathrm{x}}\right)_{2} \mathrm{O}_{7}(\mathrm{x}=0.1,0.2)$ compound during sample heating.

The temperature dependence of the ultrasound damping coefficient for the $\mathrm{Bi}_{2}\left(\mathrm{Sn}_{1-}\right.$ $\left.{ }_{x} \mathrm{Fe}_{\mathrm{x}}\right)_{2} \mathrm{O}_{7}(\mathrm{x}=0.1)$ sample is qualitatively described by a linear function up to $\mathrm{T}=430 \mathrm{~K}$. In the vicinity of the $\alpha \rightarrow \beta$ transition, at $\mathrm{T}=430 \mathrm{~K}$, the ultrasound damping coefficient is temperatureindependent.

The acoustic waves propagating in polycrystals undergo reflection, refraction, and transformation on the grain boundaries, domain walls, and structural inhomogeneities. Therefore, the damping is caused by both the absorption and scattering of the energy. In solids, the absorption can be caused by the internal friction (in this case, the ultrasound damping coefficient $\alpha$ is proportional to frequency $f$ ), heat conductivity ( $\alpha$ is proportional to $f^{2}$ ), and elastic effects ( $\alpha$ is proportional to $f$ ).

The inset in Fig. 5a shows the frequency dependence of the ultrasound damping coefficient at temperatures of 350 and $400 \mathrm{~K}$. It can be seen that $\alpha$ depends linearly on $f$. At $\mathrm{T}=$ $350 \mathrm{~K}$, the energy absorption is caused by the internal friction and, at approaching the $\alpha \rightarrow \beta$ transition, by scattering by domain walls.

The temperature dependence of the ultrasound damping coefficient for the $\mathrm{Bi}_{2}\left(\mathrm{Sn}_{1-}\right.$ $\left.{ }_{\mathrm{x}} \mathrm{Fe}_{\mathrm{x}}\right)_{2} \mathrm{O}_{7}(\mathrm{x}=0.2)$ sample (Fig. 5b) contains some anomalies. The pronounced symmetric peak at 
a temperature of $350 \mathrm{~K}$ is consistent with the anomalies in the temperature dependence of the thermal expansion coefficient in the range of 320-380 K (Fig. 4). A part of domains containing iron ions start rearranging at $\mathrm{T}=350 \mathrm{~K}$ and the whole sample becomes single phase ( $\beta$ phase) at $\mathrm{T}=430 \mathrm{~K}$. With an increase of the iron concentration, the beginning of the phase transition shifts toward lower temperatures.

Thus, the comparison of the acoustic parameters with the behavior of the temperature dependence of the thermal expansion coefficient of the sample and IR spectroscopy data in the low-temperature region suggests that the observed anomalies are indicative of the occurrence of the structural phase transition from the monoclinic to triclinic structure.

\section{Conclusions}

Upon maximum substitution of tin by iron in bismuth pyrostannate, the compound undergoes the low-temperature shift type structural transition at $140 \mathrm{~K}$, which is related to the softening and splitting of the stretching mode of the $\mathrm{Bi}-\mathrm{O}^{\prime}$ vibrations. This transition is accompanied by the crystal lattice compression and maximum in the temperature dependence of the thermal expansion coefficient.

In the temperature range of 230-280 K, the compound undergoes a series of phase transitions caused by the step-by-step transformation of the triclinic crystal structure to the monoclinic one due to the stochastic distribution of iron ions over the sample. The transition is accompanied by the softening of the stretching mode of octahedra and maxima in the temperature dependences of the thermal expansion and ultrasound damping coefficients.

The substitution of tin ions by iron ions leads to the range of phase transition from the monoclinic to cubic structure in the temperature range of 330-440 K, which is accompanied by the softening of the stretching modes of oxygen octahedra and maxima in the temperature dependences of the ultrasound damping coefficient.

\section{Author contributions}

S.S. Aplesnin supervised the experimental work. L.V. Udod, M.N. Sitnikov, O.B. Romanova, M.N. Molokeev performed all experimental work. The manuscript was written and discussed by all authors.

\section{Acknowledgments}

The reported study was funded by RFBR according to the research project №18-5200009 Bel_a; The reported study was funded by Russian Foundation for Basic Research, Government of Krasnoyarsk Territory, Krasnoyarsk Regional Fund of Science№ 18-42-240001 r_a, to the research project: «Inversion of the sign of the components of the magnetoelectric tensor on the temperature in films of bismuth garnet ferrite replaced by neodymium». This work is part of the research program the state order № 3.5743.2017/6.7.

\section{References}

[1] W.R. Cook, Jr. and H. Jaffe, Ferroelectricity in oxides of fluorite structure, Phys. Rev. 88 (1952) 1426. 
[2] E. Buixaderas, S. Kamba, J. Petzelt, Lattice Dynamics and Central-Mode Phenomena in the Dielectric Response of Ferroelectrics and Related Materials, Ferroelectrics 308 (2004) 131-192. htts://doi:10.1080/00150190490508909.

[3] M. Hanawa, Y. Muraoka, T. Tayama, T. Sakakibara, J. Yamaura, Z. Hiroi, Superconductivity at $1 \mathrm{~K}$ in $\mathrm{Cd}_{2} \mathrm{Re}_{2} \mathrm{O}_{7}$, Phys. Rev. Lett. 87 (2001) 187001.

https://doi.org/10.1103/PhysRevLett.87.187001

[4] M.P. van Dijk, K.J. de Vries, A.J Burggraaf, Oxygen ion and mixed conductivity in compounds with the fluorite and pirochlore strucrure, Solid State Ionics 9-10 (1983) 913-920.

[5] M.A. Subramanian, B.H. Toby, A.P. Ramirez, W.J. Marshall, A.W. Sleight, G.H. Kwei, Colossal magnetoresistance without $\mathrm{Mn}^{3+} / \mathrm{Mn}^{4+}$ double exchange in the stoichiometric pyrochlore $\mathrm{Tl}_{2} \mathrm{Mn}_{2} \mathrm{O}_{7}$, Science 273 (1996) 81-84. https://doi.org/10.1126/science.273.5271.81.

[6] A.W. Sleight, J.L. Gillson, Platinum metal pyrochlores of the type $\mathrm{Tl}_{2} \mathrm{M}_{2} \mathrm{O}_{7}$, Mater. Res. Bull. 6 (1971) 781-784. https://doi.org/10.1016/0025-5408(71)90114-0.

[7] A.P. Ramirez, A. Hayashi, R.J. Cava, R. Siddharthan, B.S. Shastry, Zero-point entropy in 'spin ice', Nature 399 (1999) 333-335.

[8] N.P. Laverov, S V. Yudintsev, T.S. Livshits, S.V. Stefanovsky, A.N. Lukinykh, R.C. Ewing, Synthetic minerals with the pyrochlore and garnet structures for immobilization of actinidecontaining wastes, Geochem. Int. 48 (2010) 1-10. DOI: 10.1134/S0016702910010015.

[9] O. Merka, D.W. Bahnemann, M. Wark, Photocatalytic hydrogen production with nonstoichiometric pyrochlore bismuth titanate, Catal.Today 225 (2013), 102-110.

https://doi.org/10.1016/i.cattod.2013.09.009.

[10] M.A. Subramanian, G. Aravamudan, G.B. Subba Rao, Oxide pyrochlores - a review, Prog. Solid State Chem. 15 (1983) 55-143. http://dx.doi.org/10.1016/0079-6786(83)90001-8/

[11] R.S. Roth, Pyrochlore-tape compounds containing double oxides of trivalent and tetravalent ions, J. Res. Natl. Bur. Stand. 56 (1956) 17-25.

[12] I.R. Evans, J.A.K. Howard, J.S.O. Evans, $\alpha-\mathrm{Bi}_{2} \mathrm{Sn}_{2} \mathrm{O}_{7}-$ a 176 atom crystal structure from powder diffraction data, J. Mat. Chem. 13 (2003) 2098. DOI:10.1039/B305211G.

[13] B.J. Kennedy, Ismunandar, M.M. Elcombe, Structure and bonding in $\mathrm{Bi}_{2} \mathrm{Sn}_{2} \mathrm{O}_{7}$, Mater. Sci. Forum 278 (1998) 762-767.

[14] R.D. Shannon, J.D. Bierlein, J.L. Gillson, G.A. Jones, A.W. Sleight, Polymorphism in $\mathrm{Bi}_{2} \mathrm{Sn}_{2} \mathrm{O}_{7}$, J. Phys. Chem. Solids 41 (1980) 117-122. https://doi.org/10.1016/00223697(80)90041-4.

[15] V. Kahlenberg, T. Zeiske, Structure of $\gamma$-Bi2Sn2O7 by high-temperature powder neutron diffraction, Z. Kristallogr. 212 (1997) 297-301.

[16] R.H. Jones, K.S. Knight, The structure of $\gamma$-Bi2Sn2O7 at $725^{\circ} \mathrm{C}$ by high-resolution neutron diffraction: implications for bismuth (III)-containing pyrochlores, J. Chem. Soc. Dalton Trans. 15 (1997) 2551-2556. DOI:10.1039/A702079A.

[17] A. Salamat, A.L. Hector, P.F. McMillan, C. Ritter, Structure, bonding, and phase relations in $\mathrm{Bi}_{2} \mathrm{Sn}_{2} \mathrm{O}_{7}$ and $\mathrm{Bi}_{2} \mathrm{Ti}_{2} \mathrm{O}_{7}$ pyrochlores: new insights from high pressure and high temperature studies, Inorg. Chem. 50 (2011) 11905-13. DOI: 10.1021/ic200841v.

[18] M. Fischer, T. Malcherek, Ul.B.P. Blaha and K. Schwarz, Structure and stability of $\mathrm{Cd}_{2} \mathrm{Nb}_{2} \mathrm{O}_{7}$ and $\mathrm{Cd}_{2} \mathrm{Ta}_{2} \mathrm{O}_{7}$ explored by a binitio calculations, Phys. Rev. 78 (2008) 014108. DOI: 10.1103/PhysRevB.78.014108.

[19] Z. Zou, J. Ye, H. Arakawa, Synthesis, magnetic and electrical transport properties of the $\mathrm{Bi}_{2} \mathrm{InNbO}_{7}$ compound, Solid State Commun. 116 (2000) 259-263. 
[20] Z.G. Zou, J.H. Ye, R. Abe, H. Arakawa, Photocatalytic decomposition of water with $\mathrm{Bi}_{2} \mathrm{InNbO}_{7}$ Catal. Lett. 68 (2000) 235-239.

[21] S.S. Aplesnin, L.V. Udod, M.N. Sitnikov, Electronic transition, ferroelectric and thermoelectric properties of bismuth pyrostannate $\mathrm{Bi}_{2}\left(\mathrm{Sn}_{0.85} \mathrm{Cr}_{0.15}\right)_{2} \mathrm{O} 7$, Ceramics International 44 (2018) 1614-1620. http://dx.doi.org/10.1016/j.ceramint.2017.10.082.

[22] S.S. Aplesnin, L.V. Udod, M.N. Sitnikov, V.V. Kretinin, M.S. Molokeev, N. MironovaUlmane, Dipole glass in chromium-substituted bismuth pyrostannate, Mater. Res. Express 5 (2018) 115202. https://doi.org/10.1088/2053-1591/aaddd9

[23] S.S. Aplesnin, L.V. Udod, M.N. Sitnikov, M.S. Molokeev, L.S. Tarasova, K.I. Yanushkevich, Magnetic, dielectric, and transport properties of bismuth pyrostannate $\mathrm{Bi}_{2}\left(\mathrm{Sn}_{0.9} \mathrm{Mn}_{0.1}\right)_{2} \mathrm{O}_{7}$, Phys. Solid State 59 (2017) 2268-2273. DOI: 10.1134/S1063783417110038. [24] Ismunandar, B.J. Kennedy, B.A. Hunter, T. Vogt, Bonding and structural variations in doped $\mathrm{Bi}_{2} \mathrm{Sn}_{2} \mathrm{O}_{7}, \quad$ J. Solid State Chem. $131 \quad$ (1997) 317-325. https://doi.org/10.1006/jssc.1997.7387.

[25] Bruker AXS TOPAS V4: General profile and structure analysis software for powder diffraction data. - User's Manual. Bruker AXS, Karlsruhe, Germany. 2008.

[26] H.C. Gupta, S. Brown, N. Rani, V.B. Gohel, J. Raman Spectrosc. 32, (2001) 41-44. doi 10.1002/1097-4555(200101)32:1<41::AID-JRS664>3.0.CO;2-R.

[27] D.J. Arenas, L.V. Gasparov, Wei Qiu, J.C. Nino, Charles H. Patterson, D. B. Tanner, Raman study of phonon modes in bismuth pyrochlores, Phys. Rev. B 82 (2010) 214302. https://doi.org/10.1103/PhysRevB.82.214302.

[28] T. A. Vanderah, I. Levin, M. W. Lufaso, An Unexpected Crystal-Chemical Principle for the Pyrochlore Structure, Eur. J. Inorg. Chem. 14 (2005) 2895-2901. https://doi.org/10.1002/ejic.200500234.

[29] V. Krayzman, I. Levin, and J.C. Woicik, Local Structure of Displacively Disordered Pyrochlore Dielectrics, Chem. Mater. 19 (2007) 932-936. DOI: 10.1021/cm062429g.

[30] V.A.M. Brabers, Infrared Spectra of Cubic and Tetragonal Manganese Ferrites, Phys. Status Solidi B 33 (1969) 563-572. DOI:10.1002/pssb.19690330209.

[31] T.T. Zhang, K.W. Li, J. Zeng, Y.L. Wang, X.M. Song, H. Wang, Synthesis and structural characterization of a series of lanthanide stannate pyrochlores, J. Phys. Chem. Solids 69 (2008) 2845-2851. doi:10.1016/j.jpcs.2008.07.014.

[32] R.X. Silva, C.W.A. Paschoal, R.M. Almedia, M. Carvalho Castro Jr., A.P. Ayala, Jeffrey T. Auletta, Michael W. Lufaso, Temperature dependence Raman spectra of $\mathrm{Bi}_{2} \mathrm{Sn}_{2} \mathrm{O}_{7}$, Vib. Spectrosc. 64 (2013) 172-177. https://doi.org/10.1016/j.vibspec.2012.05.009.

[33] R L. Withers, T.R. Welberry, A.K. Larsson, Y. Liu, L. Norén, H. Rundlöf, F.J. Brink, Local crystal chemistry, induced strain and short range order in the cubic pyrochlore $\left(\mathrm{Bi}_{1.5-\alpha} \mathrm{Zn}_{0.5-}\right.$ $\left.{ }_{\beta}\right)\left(\mathrm{Zn}_{0.5-\gamma} \mathrm{Nb}_{1.5-\delta}\right) \mathrm{O}(7-1.5 \alpha-\beta-\gamma-2.5 \delta)(\mathrm{BZN}), \quad$ J. Solid State Chem. 177 (2004) 231-244. DOI:10.1016/j.jssc.2003.07.005.

[34] Ronald A. McCauley, Infrared-absorption characteristics of the pyrochlore structure, JOSA 63 (1973) 721-725. https://doi.org/10.1364/JOSA.63.000721.

[35] A.L. Hector, S.B. Wiggin, Synthesis and structural study of stoichiometric $\mathrm{Bi}_{2} \mathrm{Ti}_{2} \mathrm{O}_{7}$ pyrochlore, J. Solid State Chem. 177 (2004) 139-145. https://doi.org/10.1016/S00224596(03)00378-5.

[36] M. Avdeev, M.K. Hass, J.D. Jorgensen, R.J. Cava, Static disorder from lone-pair electrons in $\mathrm{Bi}_{2-\mathrm{x}} \mathrm{M}_{\mathrm{x}} \mathrm{Ru}_{2} \mathrm{O}_{7-\mathrm{y}}(\mathrm{M}=\mathrm{Cu}, \mathrm{Co} ; \mathrm{x}=0,0.4)$ pyrochlores, J. Solid State Chem. 169 (2002) 24-34. https://doi.org/10.1016/S0022-4596(02)00007-5. 
[37] M. Mączka, M.L. Sanjuán, A.F. Fuentes, L. Macalik, J. Hanuza, K. Matsuhira, Z. Hiroi, Temperature-dependent studies of the geometrically frustrated pyrochlores $\mathrm{Ho}_{2} \mathrm{Ti}_{2} \mathrm{O}_{7}$ and $\mathrm{Dy}_{2} \mathrm{Ti}_{2} \mathrm{O}_{7}$, Phys. Rev. B 79 (2009) 214437. http://dx.doi.org/10.1103/PhysRevB.79.214437.

[38] Huiling Du, Xi Yao, Liangying Zhang, Structure, IR spectra and dielectric properties of $\mathrm{Bi}_{2} \mathrm{O}_{3}-\mathrm{ZnO}-\mathrm{SnO}_{2}-\mathrm{Nb}_{2} \mathrm{O}_{5}$ quarternary pyrochloreб Ceramics International 28 (2002) 231-234.

[39] F.W. Poulsen, M. Glerup, P. Holtappels, Structure, Raman spectra and defect chemistry modelling of conductive pyrochlore oxides, Solid State Ionics 135 (2000) 595-602.

[40] K.S. Aleksandrov, S.V. Misyul, M.S. Molokeev, V.N. Voronov, Structures of Distorted Phases and Critical and Noncritical Atomic Displacements of Elpasolite $\mathrm{Rb}_{2} \mathrm{KInF}_{6}$ during Phase Transitions, Phys. Solid State 51 (2009) 2505-2513. DOI: 10.1134/S1063783409120130 


\section{Figure captions}

Fig. 1 Difference XRD pattern of $\mathrm{Bi}_{2}\left(\mathrm{Sn}_{1-\mathrm{x}} \mathrm{Fe}_{\mathrm{x}}\right)_{2} \mathrm{O}_{7}, \mathrm{x}=0.2$. The upper curve shows the experimental XRD pattern; the middle curve, the theoretical XRD pattern; and the lower curve, the difference between the theoretical and experimental XRD patterns (a). Crystal structure of $\mathrm{Bi}_{2} \mathrm{Sn}_{2} \mathrm{O}_{7}$. The $\mathrm{SnO}_{6}$ fragment is shown separately, in the centre of octahedral is Sn. Symbols code: circles at the tops of the octahedra are $\mathrm{O}$ atoms, space between octahedra are $\mathrm{Bi}(\mathrm{b})$.

Fig.2 Infrared spectra of the $\mathrm{Bi}_{2}\left(\mathrm{Sn}_{1-\mathrm{x}} \mathrm{Fe}_{\mathrm{x}}\right)_{2} \mathrm{O}_{7}, \mathrm{x}=0$ (1), 0.1 (2), 0.2 (3) at temperatures $100 \mathrm{~K}$ (a), $200 \mathrm{~K}$ (b), $300 \mathrm{~K}$ (c), $400 \mathrm{~K}$ (d).

Fig. 3 The dependence of the IR phonon frequencies w1 (a) and w2 (b) of the $\mathrm{Bi}_{2}\left(\mathrm{Sn}_{1-}\right.$ $\left.{ }_{\mathrm{x}} \mathrm{Fe}_{\mathrm{x}}\right)_{2} \mathrm{O}_{7}$ for $\mathrm{x}=0$ (1), 0.1 (2), 0.2 (3) versus temperature.

Fig. 4 Thermal expansion coefficient of the $\mathrm{Bi}_{2}\left(\mathrm{Sn}_{0.8} \mathrm{Fe}_{0.2}\right)_{2} \mathrm{O}_{7}$ versus temperature.

Fig. 5 Ultrasound damping coefficient of $\mathrm{Bi}_{2}\left(\mathrm{Sn}_{1-\mathrm{x}} \mathrm{Fe}_{\mathrm{x}}\right)_{2} \mathrm{O}_{7}$ for $\mathrm{x}=0.1$ (a), $\mathrm{x}=0.2$ (b) versus temperature. Insert: frequency dependence of the ultrasound damping coefficient of $\mathrm{Bi}_{2}\left(\mathrm{Sn}_{0.9} \mathrm{Fe}_{0.1}\right)_{2} \mathrm{O}_{7}$. 


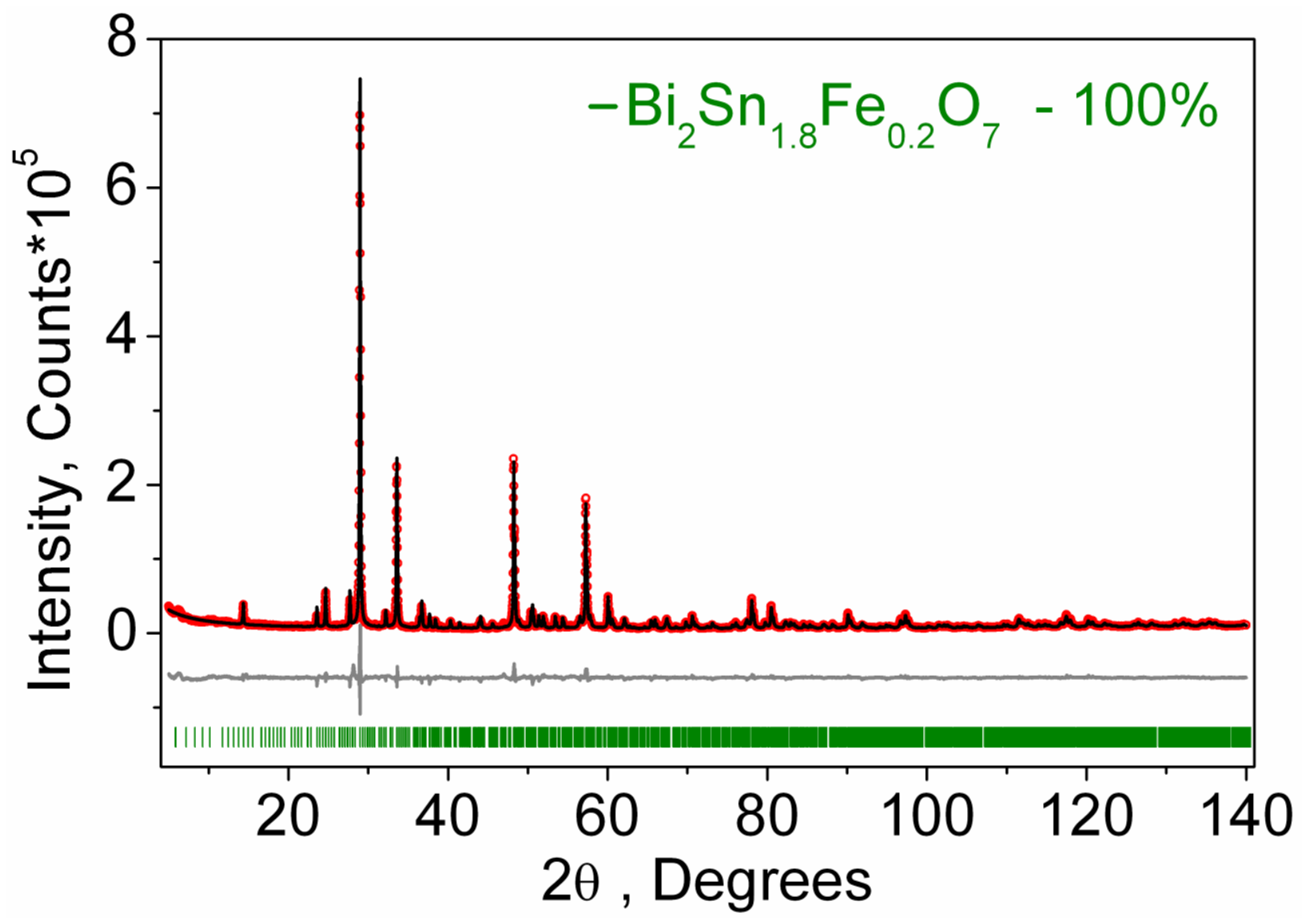

Fig.1a 

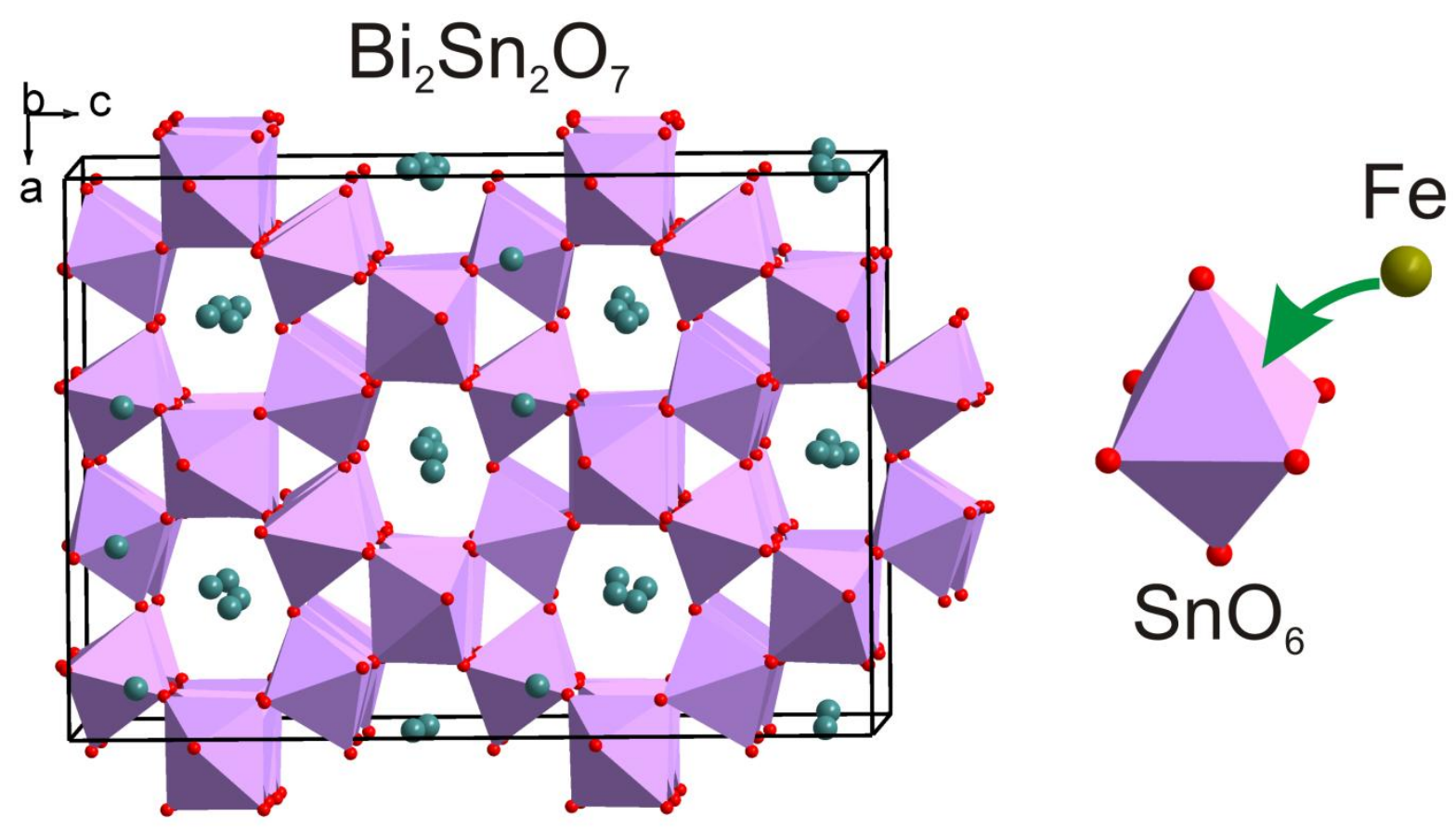

Fig 1b 

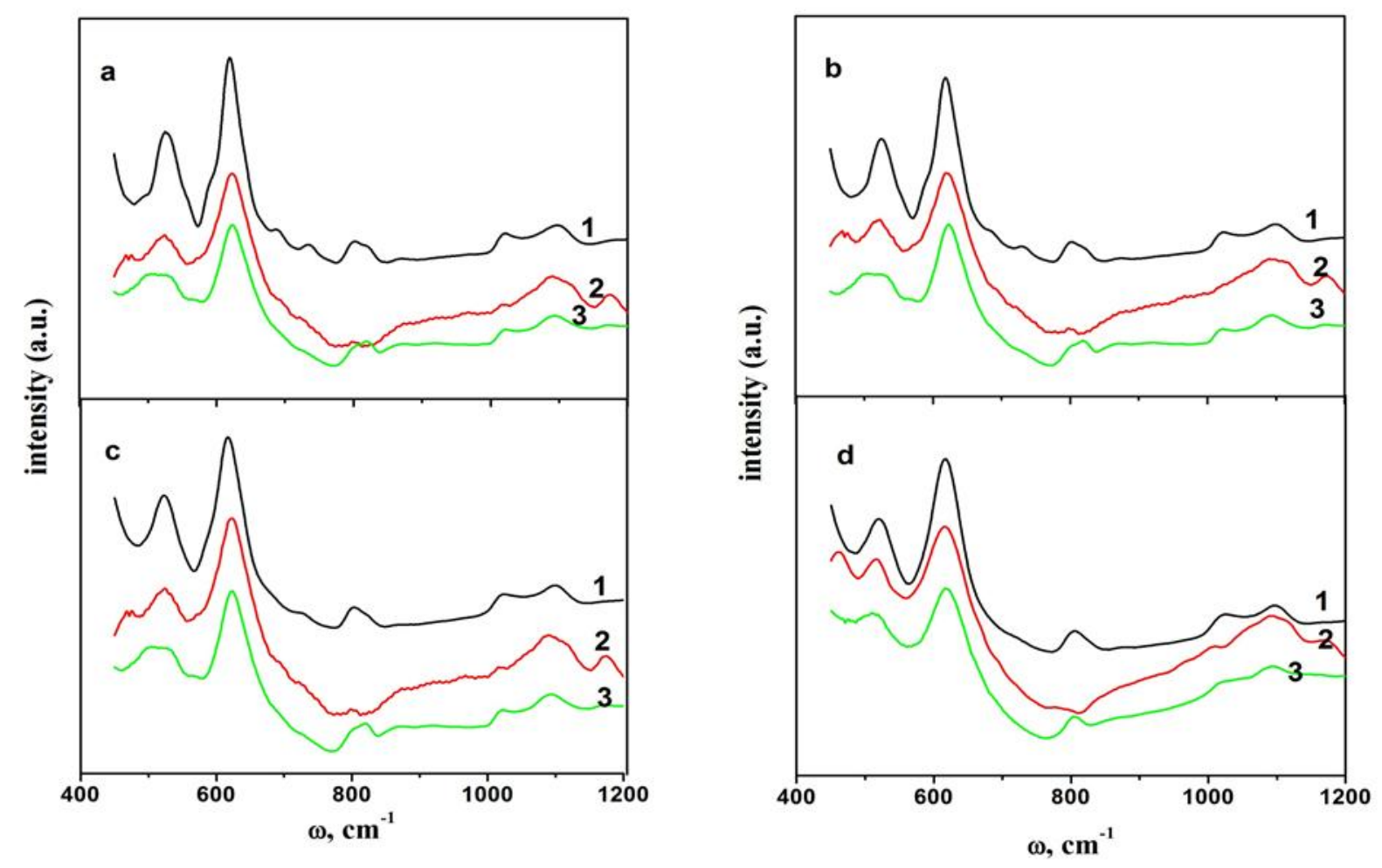

Fig.2 

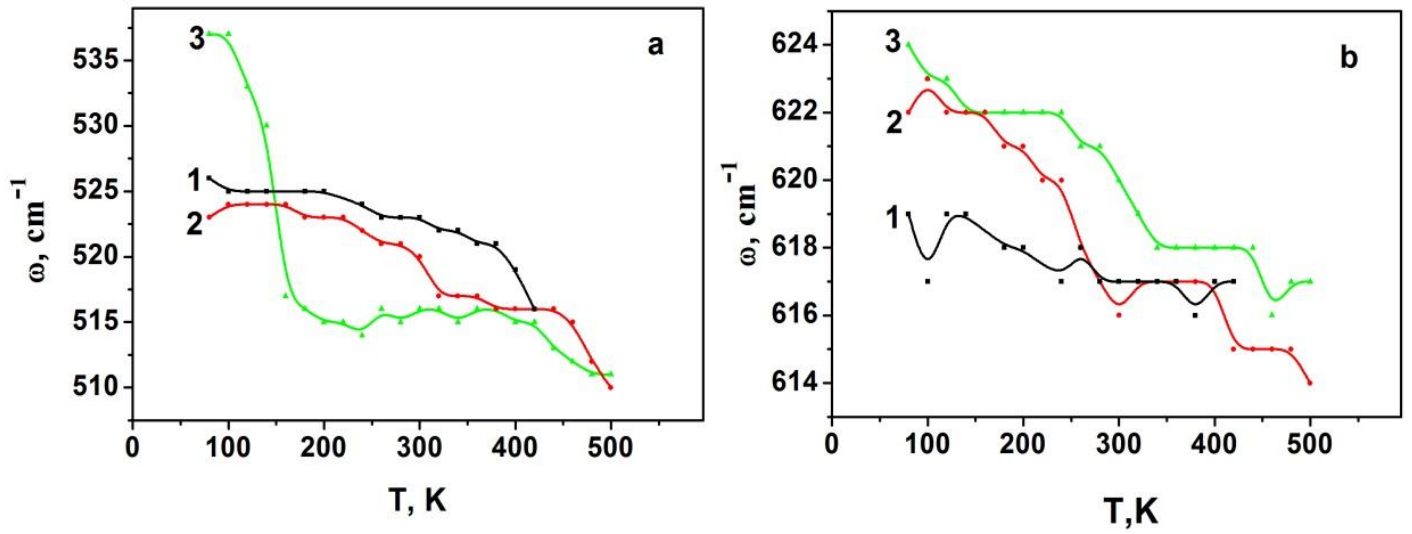

Fig. 3 


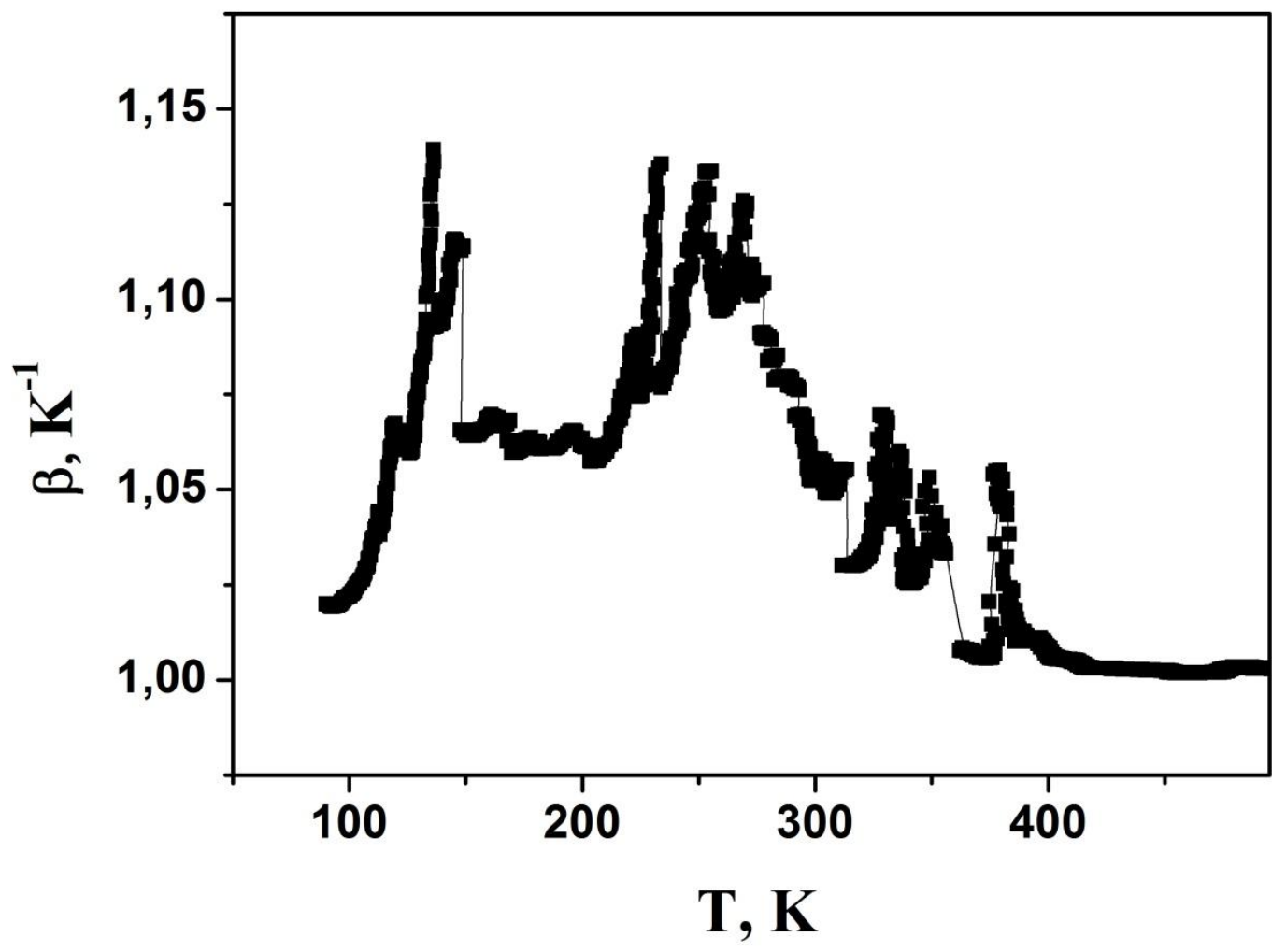

Fig.4 

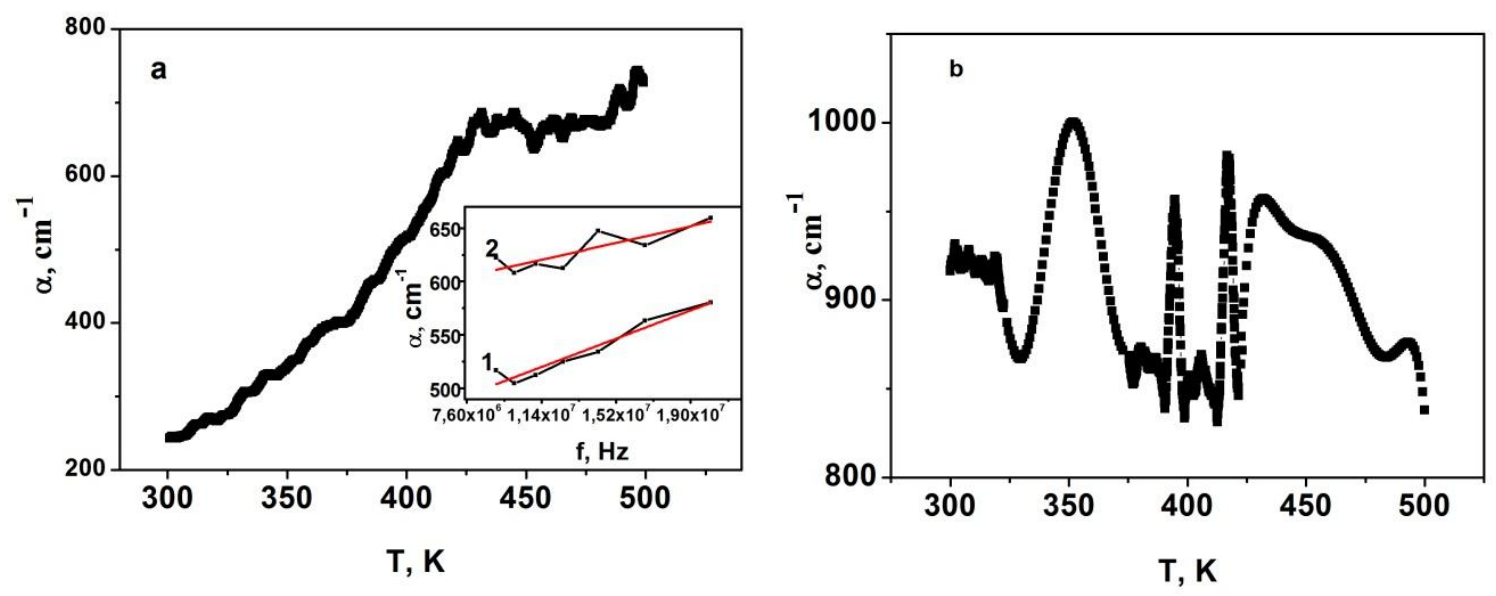

Fig.5 

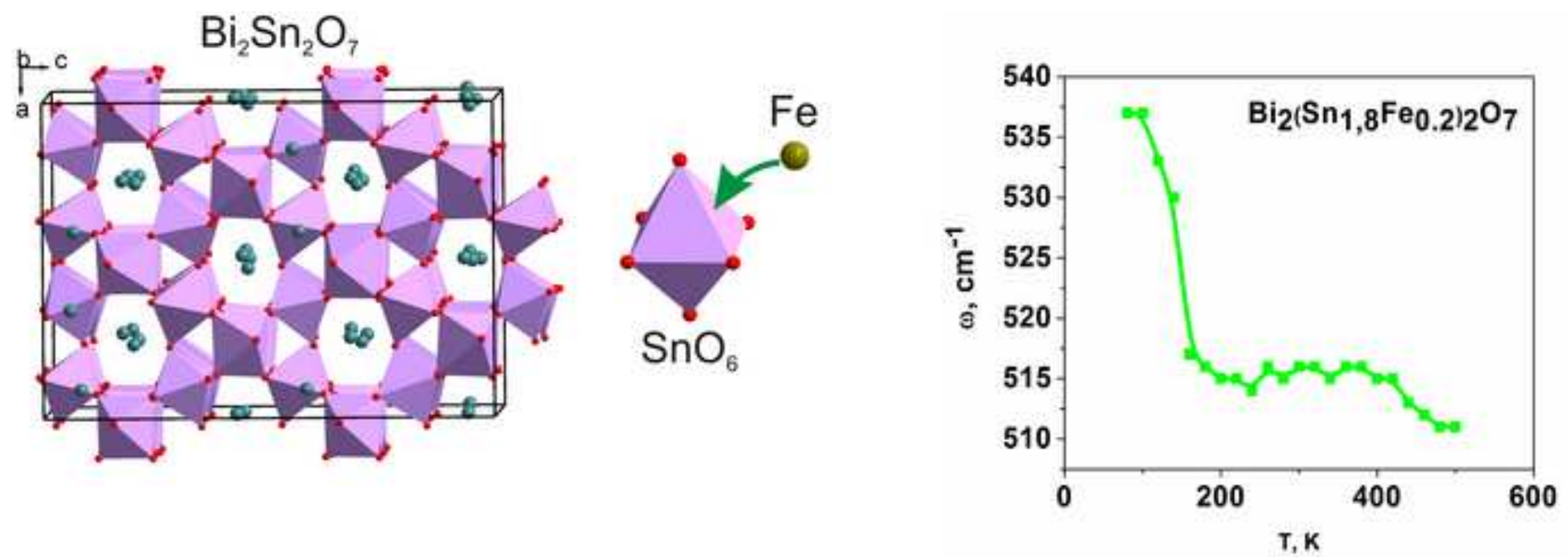


\section{Highlights}

The low-temperature shift - type structural transition and the series of phase transitions from trigonal to the monoclinic structure at the substitution of tin ions by iron ions in bismuth pyrostannate were established. 


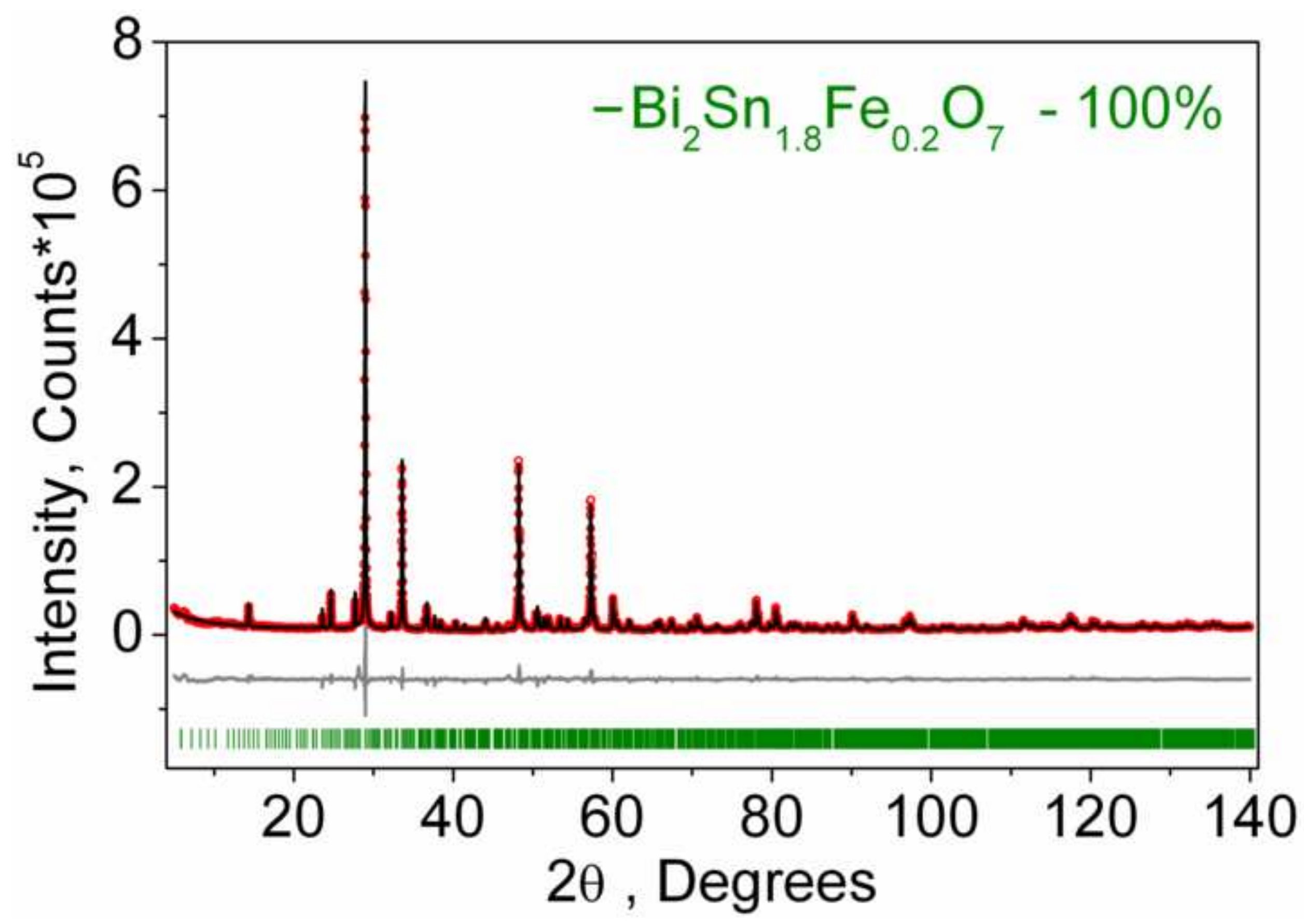



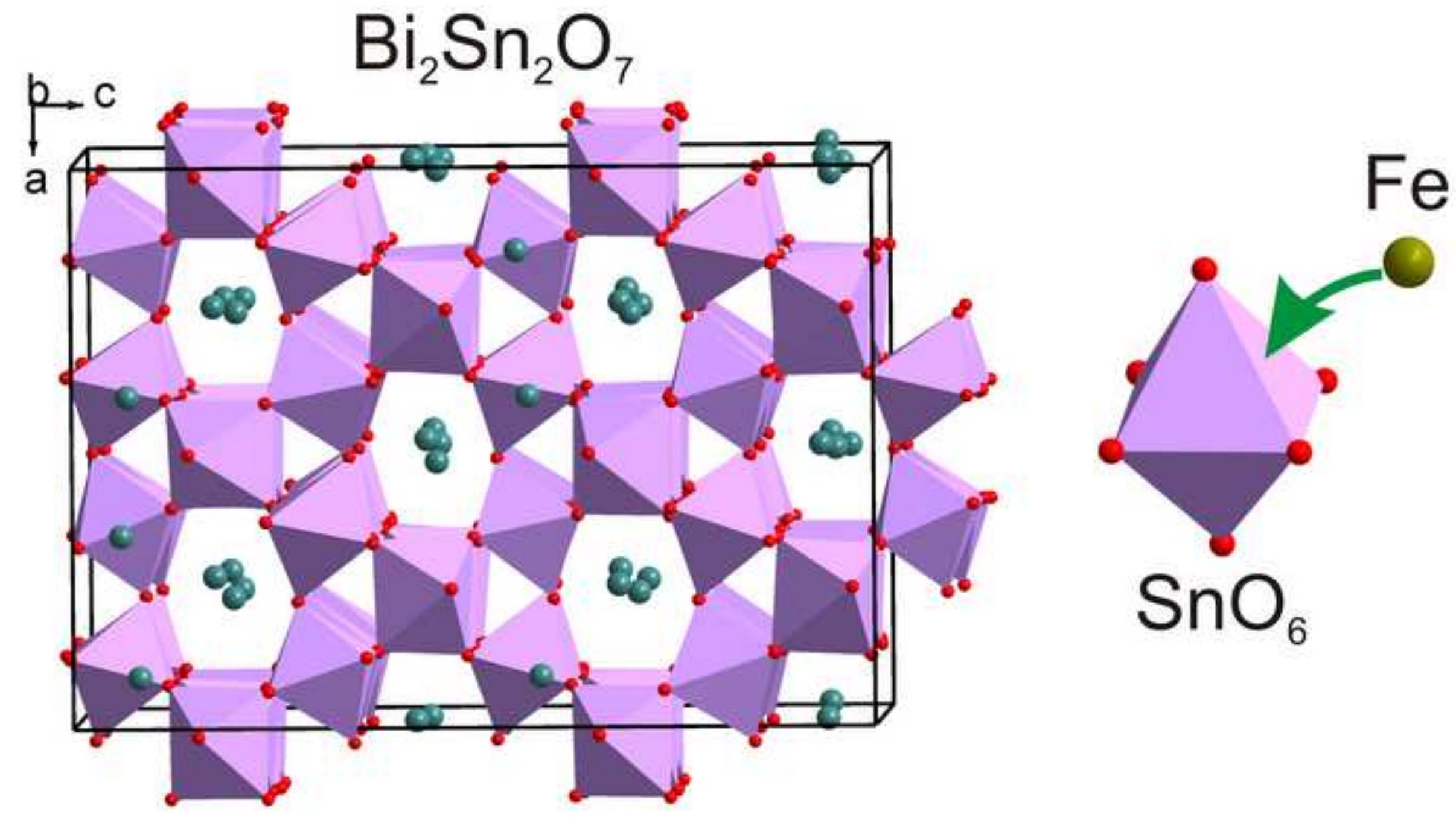

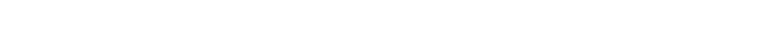

\section{$\mathrm{SnO}_{6}$}

\section{$\mathrm{Fe}$}

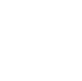



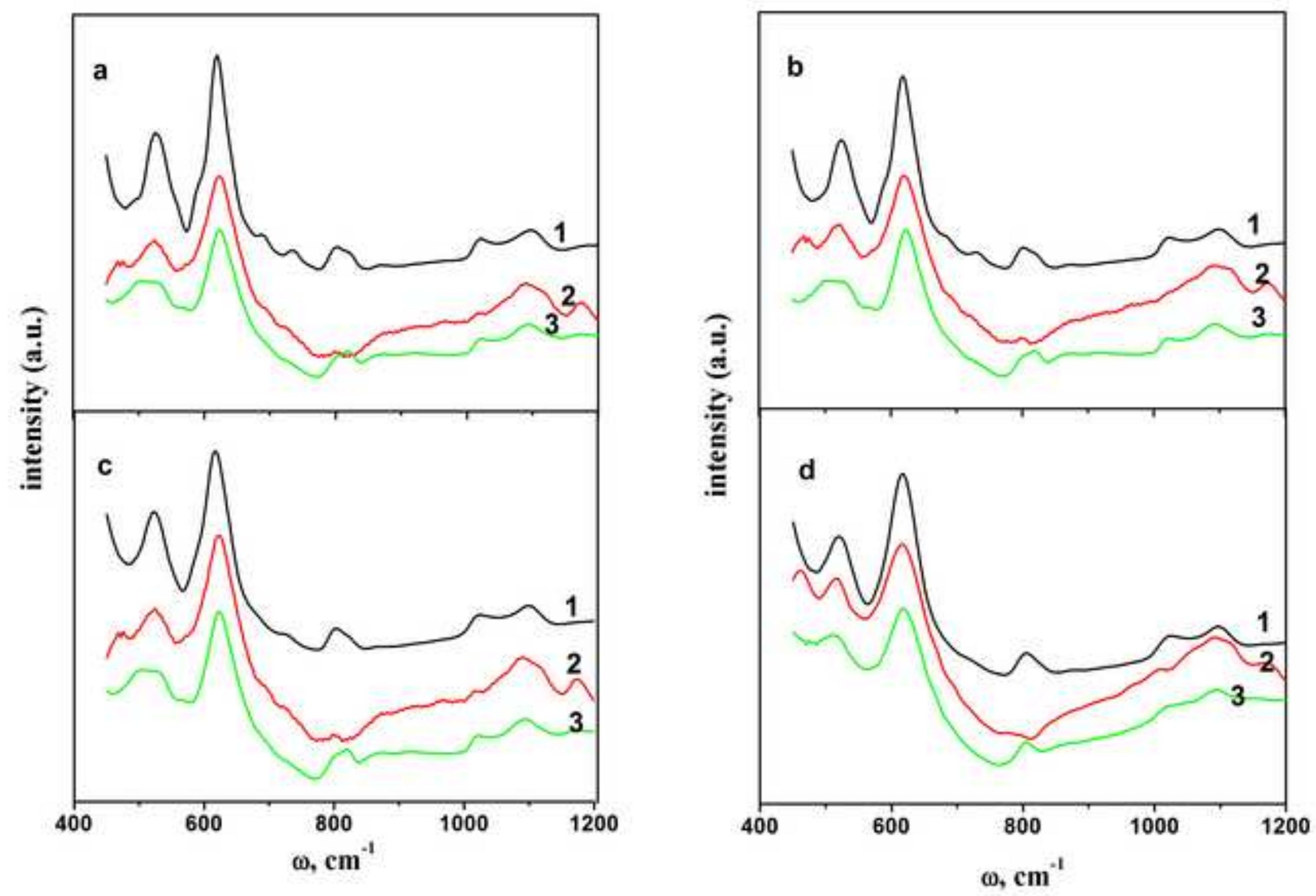

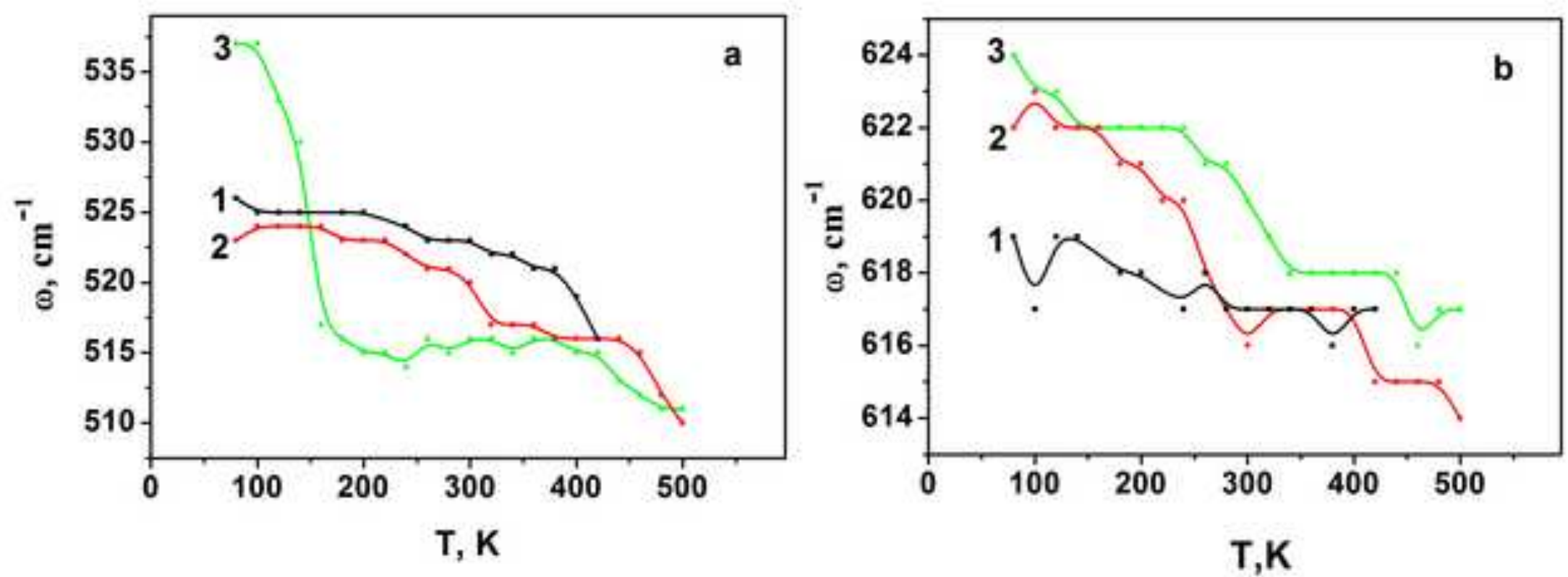


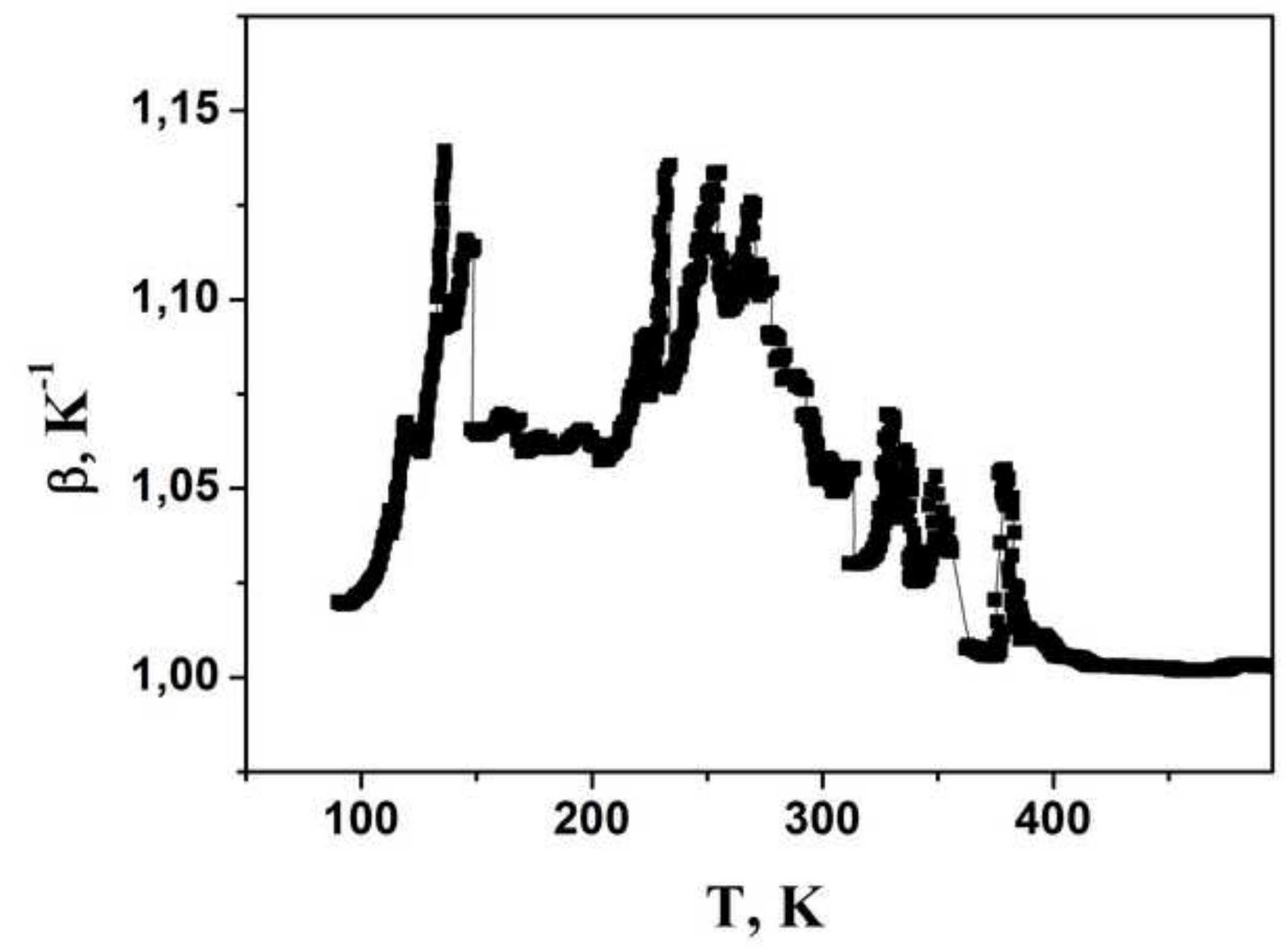

\section{Click here to download high resolution image}



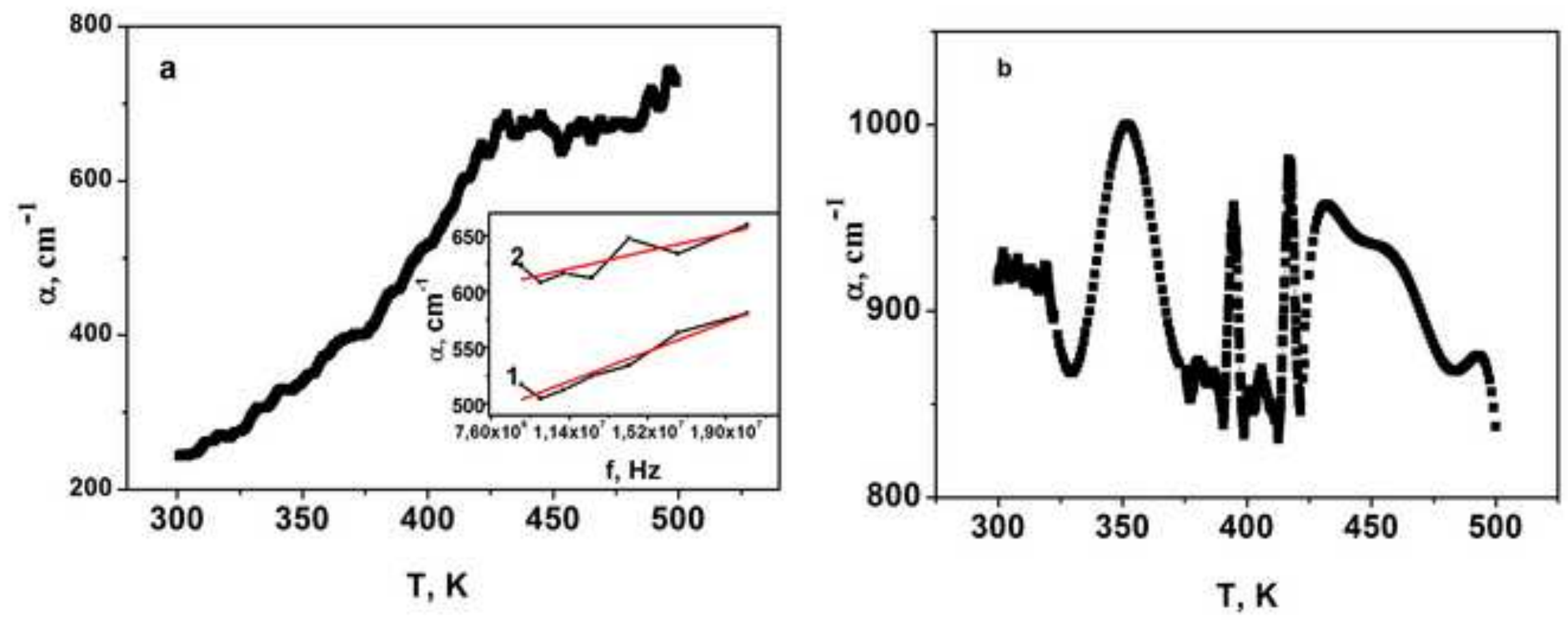